\title{
Hubungan Letak Geografis dengan Kepatuhan Pengobatan pada Pasien Hipertensi di Kabupaten Pekalongan
}

\author{
Benny Arief Sulistyanto ${ }^{1}$, Mukti Lestari Madyoratri ${ }^{2}$ \\ 1. Universitas Muhammadiyah Pekajangan Pekalongan, email: benny.arief@gmail,com \\ 2. Universitas Muhammadiyah Pekajangan Pekalongan
}

\begin{abstract}
Abstrak. Kepatuhan pengobatan hipertensi dapat dipengaruhi oleh faktor sosial-demogafik. Perbedaan fasilitas penunjuang kesehatan pada daerah dataran rendah dan dataran tinggi mengakibatkan tidak meratanya informasi dan pengobatan terkait hipertensi. Penelitian ini bertujuan untuk mengidentifikasi hubungan letak geografis dengan tingkat kepatuhan pengobatan hipertensi di Kabupaten Pekalongan. Penelitian ini merupakan studi deskirptif dengan pendekatan cross-sectional. Kuesioner The 8-item Morisky Medication Adherence Scale (MMAS-8) versi Bahasa Indonesia digunakan untuk mengukur kepatuhan pengobatan hipertensi pada 65 responden di daerah dataran tinggi dan dataran rendah. Hasil penelitian ini menemukan bahwa letak geografis mempunyai korelasi terhadap kepatuhan pengobatan hipertensi ( $p$-value $<0,01)$. Petugas kesehatan hendaknya menggunakan berbagai metode untuk meningkatkan kepatuhan pengobatan khususnya yang berlokasi di dataran rendah. Namun demikian, peningkatkan kualitas dan kuantitas fasilitas kesehatan di dataran tinggi tidak boleh diabaikan
\end{abstract}

Kata kunci: kepatuhan pengobatan, hipertensi, MMAS-8, letak geografis

\section{Relationship between Geographical Location and Medication Adherence in Hypertensive Patients in Pekalongan District}

Abstract. Medication adherence among hypertensive patients can be influenced by socio-demographic factors. The differences in health care facilities in the lowlands and highlands create a gap of information and treatment related to hypertension treatments. The purpose of this study is to identify the relationship between geographical location and medication adherence in Pekalongan Regency. A descriptive study with a cross-sectional approach was used. The Indonesian version of the Morisky Medication Adherence Scale (MMAS-8) questionnaire was used to measure the adherence of medication treatment among 65 respondents in the highlands and lowlands. The results of this study revealed that geographical location was highly correlated with medication adherence ( $p$-value $<0.01)$. Health workers should use various methods to improve medication adherence, especially those located in the lowlands. Although, improving the quality and quantity of health facilities in the highlands should not be ignored

Keywords: medication adherence, hypertension, MMAS-8, geographical location

\section{Pendahuluan}

Hipertensi menjadi salah satu penyakit kardiovaskuler yang menjadi penyebab utama mortalitas dan disabilitas di dunia (DINKES Kab.Fitrina et al., 2015). Berdasarkan data Global Status Report on Noncommunicable Diseases 2010 - WHO, 40\% pasien hipertensi terdapat pada negara-negara berkembang, sedangkan negara maju sekitar $35 \%$ (Alwan, 2011). Penderita hipertensi akan terus meningkat yang bertanggung jawab terhadap berbagai penyakit kardiovaskular (WHO, 2013). Lebih dari satu miliar orang di seluruh dunia menderita hipertensi yang menyebabkan kematian 17 juta jiwa tiap tahunnya (Adeloye et al., 2015). Indonesia sebagai salah satu negara berkembang yang mempunyai prevalensi hipertensi yang tinggi dan terus meningkat dari tahun ke tahun. Berdasarkan data Riset Kesehatan Dasar, prevalensi hipertensi di Indonesia mencapai $25,8 \%$ pada tahun 2013 dan meningkat pada tahun 2018 menjadi 34,1\% (Kemenkes RI, 2018).

Meningkatnya penyakit hipertensi ini meliputi berbagai macam faktor akibat gaya hidup tidak sehat seperti kurangnya aktifitas fisik, konsumsi rokok, diet tinggi lemak dan garam (Fitrina et al., 2015, Ghosh et al., 2013, Khayyat et al., 2017). 
Son et al. (2012) menambahkan bahwa faktor tempat tinggal juga mempengaruhi prevalensi hipertensi. Dataran rendah cenderung mengalami industrialisasi dan modernisasi yang cepat sehingga memicu gaya hidup tidak sehat sehingga berkontribusi terhadap meningkatnya tekanan darah, oleh karenanya kejadian hipertensi lebih banyak di darah dataran rendah daripada daerah pegunungan. Penelitian lain oleh (Saputra and Anam, 2016) menyimpulkan bahwa tingginya konsumsi natrium dan makanan laut tinggi kolesterol pada masyarakat pesisir pantai meningkat kejadian hipertensi. Di Kabupaten Pekalongan - Jawa Tengah, prevalensi hipertensi di dataran rendah lebih dari empat kali lipat dibandingkan dengan dataran tinggi. Sebagai contoh, data hipertensi pada daerah dataran rendah di Puskesmas Bojong I berjumlah 751 jiwa kedua di Puskesmas Karanganyar berjumlah 557 jiwa dan yang ketiga di Puskesmas Kedungwuni II berjumlah 416 jiwa. Hal ini jauh berbeda dengan daerah dataran tinggi seperti di Puskesmas Doro II berjumlah 150 jiwa kedua di Puskesmas Doro I berjumlah 132 dan yang ketiga di Puskesmas Kandangserang berjumlah 97 jiwa (DINKES Kab. Pekalongan, 2017).

Sari (2017) menyatakan bahwa kontrol tekanan secara rutin dan kepatuhan terhadap pengobatan hipertensi sangatlah penting karena dapat mencegah komplikasi seperti stroke dan serangan jantung. Konsumsi obat secara rutin sangat diperlukan untuk mengendalikan tekanan darah pada penderita hipertensi karena sulitnya untuk melakukan aktivitasaktivitas dalam mengendalikan hipertensi (Ardiansyah, 2012). Tingkat kepatuhan minum obat dapat dipengaruhi oleh jarak rumah dengan pelayanan kesehatan. Penderita hipertensi yang tinggal dekat dengan fasilitas pelayanan kesehatan seperti rumah sakit maupun puskesmas cenderung lebih patuh (52,4\% lebih tinggi) dari pada penderita yang jauh dari fasilitas pelayanan kesehatan.
Mayoritas fasilitas pelayanan kesehatan tersedia di dataran rendah yang merupakan daerah perkotaan. Di Kabupaten Pekalongan semua rumah sakit berlokasi di daerah dataran rendah dan hanya sebagian kecil Puskesmas yang ada di daerah dataran tinggi itu pun dengan tenaga kesehatan yang terbatas. Tingkat kepatuhan pengobatan hipertensi terkait dengan letek geografis juga masih jarang diteliti. Oleh karena itu, perbedaan kepatuhan pengobatan penyakit hipertensi berdasarkan lokasi geografis perlu diteliti untuk mengidentifikasi keberhasilan pengendalian hipertensi yang merata dan menyeluruh.

\section{Metode}

Penelitian ini dilakukan di wilayah kerja dua Puskesmas yaitu Puskesmas Doro II yang terletak pada ketinggian 381 meter dpl (Pemkab Pekalongan, 2011b) dan Bojong I dengan letak ketinggian 50 meter dpl (Pekalongan, 2011a). Kasenda et al. (2014) menyakatakan bahwa suatu tempat disebut dataran tinggi apabila daerah tersebut mempunyai ketinggian lebih dari daerah sekitarnya yaitu pada ketinggian lebih dari 200 meter dpl. Survey dilakukan di kedua wilayah tersebut pada bulan 29 Juli -6 Agustus 2018 dengan menggunakan kuesioner kuesioner MMAS 8 (Medication Morisky Adherence Scale) versi Bahasa Indinesia (Puspita, 2016) pada 65 responden. 25 responden yang bertempat tinggal di dataran tinggi dan 40 responden yang tinggal di dataran rendah dengan kriteria: pasien hipertensi yang bersedia menjadi responden dan dapat berkomunikasi dengan baik. Kriteria eksklusi pada penelitian ini adalah pasien yang mengalami komplikasi akibat hipertensi seperti stroke, penyakit jantung, gagal ginjal, dan komplikasi hipertensi lainnya. Kemudian data dianalisis dengan uji spearman rank dengan menggunakan software statistic (SPSS). 


\section{Hasil Penelitian}

1. Karakteristik responden

Mayoritas responden dalam penelitian ini adalah lansia baik di daerah dataran tinggi maupun dataran rendah dengan proporsi lebih dari 50\%. Pada penelitian ini perempuan lebih banyak menderita hipertensi yaitu $60 \%$ padadataran tinggi dan $67,5 \%$ pada dataran rendah. Terkait dengan tingkat pendidikan, sebagian besar responden pada kedua wilayah merupakan pendidikan dasar dengan pekerjaan sebagai petani/pedagang/buruh. Responden pada dataran tinggi menderita hipertensi kurang dari 5 tahun sebanyak $52 \%$ dengan rata-rata tekanan darah 166/100 mmHg, sedangkan pada dataran rendah responden yang menderita hipertensi kurang dari lima tahun sebesar $67,5 \%$ dengan rata-rata tekanan darah 165/97 mmHg. Adapun karakteristik responden digambarakan pada tabel di bawah ini.

Tabel 1

Distribusi Karakteristik Kepatuhan

Pengobatan Pasien Hipertensi dataran tinggi di Puskesmas Doro II dan dataran rendah

\begin{tabular}{|c|c|c|c|c|}
\hline \multirow[t]{3}{*}{ Karakteristik } & \multicolumn{4}{|c|}{ Letak Geografis } \\
\hline & \multicolumn{2}{|c|}{$\begin{array}{c}\text { Dataran } \\
\text { Tinggi }\end{array}$} & \multicolumn{2}{|c|}{$\begin{array}{l}\text { Dataran } \\
\text { Rendah }\end{array}$} \\
\hline & $\mathbf{N}$ & $\%$ & $\mathbf{N}$ & $\%$ \\
\hline \multicolumn{5}{|l|}{ Umur } \\
\hline $30-40$ & 1 & 4 & 3 & 7.5 \\
\hline 41-50 & 4 & 16 & 7 & 17.5 \\
\hline $51-60$ & 7 & 28 & 12 & 30 \\
\hline$>60$ & 13 & 52 & 18 & 55 \\
\hline \multicolumn{5}{|l|}{ Jenis kelamin } \\
\hline Laki-laki & 10 & 40 & 13 & 32.5 \\
\hline Perempuan & 15 & 60 & 27 & 67.5 \\
\hline \multicolumn{5}{|l|}{ Pendidikan } \\
\hline Pendidikan Dasar & 21 & 84 & 24 & 60 \\
\hline $\begin{array}{l}\text { Pendidikan } \\
\text { Menengah }\end{array}$ & 4 & 16 & 14 & 35 \\
\hline Pendidikan Tinggi & & & 2 & 5 \\
\hline \multicolumn{5}{|l|}{ Pekerjaan } \\
\hline Tidak Bekerja & 2 & 8 & 1 & 2.5 \\
\hline $\begin{array}{l}\text { Petani/pedagang/buru } \\
\text { h }\end{array}$ & 23 & 92 & 24 & 60 \\
\hline PNS/TNI/Polri & - & - & 4 & 10 \\
\hline Wiraswasta & - & - & 11 & 27.5 \\
\hline $\begin{array}{l}\text { Lama menderita } \\
\text { hipertensi }\end{array}$ & & & & \\
\hline
\end{tabular}

\begin{tabular}{|c|c|c|c|c|}
\hline \begin{tabular}{|c|c|c|}
\hline 5 Tahun \\
\hline$<5$ Tahun
\end{tabular} & 13 & 52 & 27 & 67.5 \\
\hline Tekanan darah & 12 & 48 & 13 & 32.5 \\
\hline & Mean & Mean $165 / 97$ \\
\hline & $\begin{array}{c}166 / 100 \\
\text { mmHg }\end{array}$ & mmHg \\
\hline
\end{tabular}

2. Hubungan letak geografis dengan kepatuhan

Pada gambar 1 menunjukkan bahwa pada dataran rendah mayoritas penderita hipertensi mempunyai tingkat kepatuhan pengobatan hipertensi yang rendah dibandingkan dengan dataran tinggi. Akan tetapi, kedua wilayah mempunyai karakteristik tingkat kepatuhan yang sama.

Gambar 1. Gambaran kepatuhan pengobatan pada penderita hipertensi di dataran tinggi vs dataran rendah $(\mathrm{N}=65)$

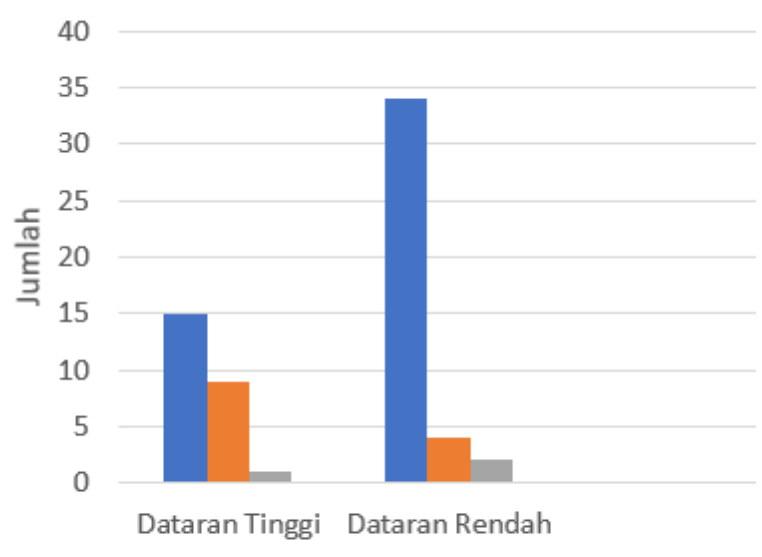

\section{Kepatuhan pengobatan \\ - Rendah $\quad$ Sedang $\quad$ Tinggi}

Uji statistik dengan menggunakan spearman's rank correlation menunjukkan bahwa terdapat hubungan yang signifikan antara letak geografis dengan tingkat kepatuhan pengobatan penyakit hipertensi dengan $p$-value $<0,01$ dengan tingkat kekuatan korelasi cukup (-0,337). Nilai koefisian korelasi yang negatif menandakan bahwa hubungan kedua variabel tersebut tidak searah. Oleh karena variabel letak dataran tinggi menjadi acuan dalam penelitian ini maka berarti bahwa jika tingkat kepatuhan pada responden di dataran tinggi meningkat maka tingkat kepatuhan responden di dataran rendah akan menurun, begitu juga sebaliknya. 
Tabel 2. Hubungan letak geografis dengan tingkat kepatuhan penderita hipertensi di Kabupaten Pekalongan ( $\mathrm{N}=65)$

\begin{tabular}{|c|c|c|c|c|}
\hline \multicolumn{5}{|c|}{ Correlations } \\
\hline & & & Letak & $\begin{array}{l}\text { Tingkat } \\
\text { Kepatuhan }\end{array}$ \\
\hline \multirow[t]{6}{*}{$\begin{array}{l}\text { Spearman's } \\
\text { rho }\end{array}$} & \multirow[t]{3}{*}{ Letak } & $\begin{array}{l}\text { Correlation } \\
\text { Coefficient }\end{array}$ & 1.000 & $-.337^{* *}$ \\
\hline & & $\begin{array}{l}\text { Sig. (2- } \\
\text { tailed) }\end{array}$ & . & .006 \\
\hline & & $\mathbf{N}$ & 65 & 65 \\
\hline & \multirow{3}{*}{$\begin{array}{l}\text { Tingkat } \\
\text { Kepatuh- } \\
\text { an }\end{array}$} & $\begin{array}{l}\text { Correlation } \\
\text { Coefficient }\end{array}$ & $\begin{array}{r}- \\
.337^{* *}\end{array}$ & 1.000 \\
\hline & & $\begin{array}{l}\text { Sig. (2- } \\
\text { tailed) }\end{array}$ & .006 & . \\
\hline & & $\mathbf{N}$ & 65 & 65 \\
\hline
\end{tabular}

\section{Pembahasan}

Pada penelitian ini responden hipertensi $52 \%$ berusia lebih dari 60 tahun di daerah dataran tinggi dan $45 \%$ berusia $>60$ tahun di daerah dataran rendah. Hasil penelitian ini sejalan dengan Meshram et al. (2012) dan Ghosh et al. (2013) di India, Wang et al. (2014) di Tiongkok, Khayyat et al. (2017) di Arab Saudi dan (Son et al., 2012) di Vietnam. Hal ini menyimpulkan bahwa prevalensi hipertensi meningkat sejalan bertambahnya usia. Penelitian ini juga menyimpulkan bahwa mayoritas penderita hipertensi adalah berjenis kelamin perempuan seperti halnya dengan penelitian lain (Son et al., 2012, Meshram et al., 2012, Khayyat et al., 2017). Susan (2011) menyatakan bahwa pada usia diatas 40 tahun, hipertensi lebih banyak menyerang wanita daripada pria. Hal ini dikarenakan adanya faktor hormonal ketika wanita memasuki masa manopause karena penurunan produksi estrogen yang menyebabkan penurunan fungsi pemeliharaan struktur pembuluh darah. Namun demikian, perempuan tidak selalu menjadi mayoritas penderita hipertensi (Ghosh et al., 2013, Wang et al., 2014).

Prevalensi hipertensi di Kabupaten Pekalongan jauh lebih banyak di daerah dataran rendah dibandingkan dengan dataran tinggi (Dinkes Kab. Pekalongan, 2017) seperti halnya di Vietnam (Son et al., 2012). Kepatuhan minum obat menjadi hal yang penting dalam pengobatan hipertensi karena pasien hipertensi banyak yang memutuskan sendiri untuk tidak obat tanpa konsultasi dengan dokter (Marshall et al., 2012). AlGhurair et al. (2012) dalam systematic review-nya menyimpulkan beberapa faktor yang mempengaruhi kepatuhan dikategorikan menjadi lima domain meliputi: faktor individu pasien, kondisi pasien, terapi, sosial-ekonomi, dan sistem pelayanan kesehatan. Jarak dari pusat pelayanan kesehatan menjadi salah satu sub-domain dari faktor sosial-ekonomi yang mempengaruhi kepatuhan pengobatan pasien 3,6 kali lebih tinggi. Namun demikian, dalam hasil penelitian tersebut hanya menyebutkan faktor dukungan sosial secara umum bukan spesifik pada faktor letak geografis.

Oleh karena itu, penelitian ini mempunyai kelebihan karena penelitian bertujuan untuk menghubungkan faktor geografis dengan kepatuhan pengobatan pasien hipertensi dengan menggunakan MMAS-8 (The 8-item Morisky Medication Adherence Scale). Hasil uji statistik spearman rank menunjukkan p-value $<0,01$ yang menandakan bahwa terdapat korelasi antara letak geografis tempat tinggal pasien hipertensi dengan tingkat kepatuhan pengobatan hipertensi. Hal ini disebabkan karena penduduk wilayah dataran rendah mayoritas hidup di daerah perkotaan yang cenderung mempunyai gaya hidup tidak sehat (Son et al., 2012, Wang et al., 2014). Hasil penelitian yang berbeda dilakukan oleh Triguna and Sudhana (2013) yang menyimpulkan bahwa tingginya ketidakpatuhan pasien hipertensi di wilayah kerja Puskesmas Petang II Kabupaten Badung oleh karena sarana transportasi yang terbatas dan jarak fasilitas kesehatan yang cukup jauh. Akan tetapi, penelitian tersebut hanya mengidentifikasi pada daerah dataran tinggi saja tanpa membandingkan daerah dataran rendah.

Hasil pada penelitian ini menyimpulkan bahwa terdapat 47 dari 65 responden $(72,3 \%)$ mempunyai tingkat kepatuhan yang rendah (MMAS-8 <6), kepatuhan sedang (MMAS-8 6-7) sebesar 23\% dan 
kepatuhan tinggi (MMAS-8 = 8) hanya $4,6 \%$. Hasil yang serupa pada penelitian yang dilakukan oleh Khayyat et al. (2017) pada pusat pelayanan kesehatan (Primary Health Care) di Mekkah-Arab Saudi yang menunjukkan bahwa $54 \%$ responden mempunyai tingkat kepatuhan yang rendah (MMAS-8 <6), kepatuhan sedang (MMAS-8 6-7) sebesar 23,5\% dan kepatuhan tinggi (MMAS-8 = 8) hanya 22,5\%. Oleh karena itu, kepatuhan pasien terhadap obat antihipertensi perlu dingkatkan dengan meningkatkan pengetahuan, motivasi, skill dan faktor-faktor lainnya agar pasien dapat mematuhi anjuran dari petugas kesehatan.

Pada Gambar 1 menunjukkan bahwa tingkat kepatuhan pasien hipertensi di daerah dataran rendah mempunyai proporsi lebih besar dibandingkan dengan daerah dataran tinggi. Dari 25 responden yang bertempat tinggal di daerah dataran tinggi terdapat 13 responden $(52 \%)$ yang mempunyai tingkat kepatuhan yang rendah, sedangkan untuk responden yang bertempat tinggal di daerah dataran rendah terdapat $85 \% \quad$ (34 dari 40 responden). Jankowska-Polańska et al. (2016) menyebutkan bahwa berapa faktor yang mempengaruhi tingkat kepatuhuan pasien hipertensi meliputi tingkat tekanan darah (hypertension grade), lama penyakit, tipe pengobatan, adanya komplikasi, efikasi diri, dan faktor sosio-demografi (umur, jenis kelamin, keadaan tempat tinggal, dan tingkat pendidikan). Namun demikian, mpenelitian ini menunjukkan bahwa meski dataran rendah mempunyai dukungan fasilitas pelayanan kesehatan yang jauh lebih baik tidak dapat mejadikan masyarakat untuk patuh terhadap pengobatan.

Penelitian ini mempunyai kelemahan yaitu jumlah sampel yang sedikit dan pengukuran yang hanya dilakukan satu kali. Jumlah sampel yang sedikit dapat menjadikan hasil statistik yang cenderung melebih-lebihkan (overestimated). Pengukuran yang dilakukan satukali dengan menggunakan kuesioner juga hanya merepresentasikan hasil hanya pada saat dilakukan penelitian. Adapun, perubahan kepatuhan karena meningkatnya informasi dan sebagainya tidak di ukur.

\section{Simpulan}

Salah satu faktor yang mempengaruhi kepatuhan pengobatan hipertensi adalah lokasi geografis. Tingkat kepatuhan pengobatan hipertensi di daerah dataran rendah cenderuh lebih rendah meski dengan fasilitas kesehatan yang lebih baik dengan daerah dataran tinggi. Oleh karena itu, strategi untuk meningkatkan kepatuhan dan identifikasi faktor-faktor yang menghalangi kepatuhan pasien perlu dilakukan. Namun demikian, peningkatan kualitas dan kuantitas fasilitas pelayanan kesehatan di daerah dataran tinggi juga tidak boleh di abaikan untuk mencegah terjadinya komplikasi penyakit hipertensi akibat kurangnya dukungan fasilitas kesehatan.

\section{Ucapan Terimakasih}

Penulis berterima kasih kepada Fakultas Ilmu Kesehatan, Universitas Muhammadiyah Pekajangan Pekalongan yang telah memberikan dukungan dalam penelitian ini. Penulis juga mengucapkan terima kasih kepada Puspita yang telah memberikan ijin untuk menggunakan kuesioner MMAS 8 versi Bahasa Indonesia.

\section{Daftar Pustaka}

Adeloye, D., Basquill, C., Aderemi, A. V., Thompson, J. Y. \& Obi, F. A. J. J. O. H. 2015. An Estimate Of The Prevalence Of Hypertension In Nigeria: A Systematic Review And Meta-Analysis. 33, 230-242.

Alghurair, S. A., Hughes, C. A., Simpson, S. H. \& Guirguis, L. M. 2012. A Systematic Review Of Patient SelfReported Barriers Of Adherence To Antihypertensive Medications Using The World Health Organization Multidimensional Adherence Model. 14, 877-886.

Alwan, A. 2011. Global Status Report On

Noncommunicable Diseases 2010, World Health Organization. 
Fitrina, Y., Harysko \& Okta, R. 2015.

Hubungan Karakteristik Dan

Motivasi Pasien Hipertensi

Terhadap Kepatuhan Dalam

Menjalani Pengobatan Di Puskesmas

Talang Kabupaten Solok Tahun 2015. 2.

Ghosh, A., Sarkar, D., Mukherji, B., Pal, R. J. A. O. T. M. \& Health, P. 2013.

Prevalence And Risk Correlates Of

Hypertension Among Adult Rural

Population In Bihar. 6, 71.

Jankowska-Polańska, B., Uchmanowicz, I.,

Dudek, K. \& Mazur, G. 2016.

Relationship Between Patients'

Knowledge And Medication

Adherence Among Patients With

Hypertension. Patient Preference

And Adherence, 10, 2437-2447.

Kasenda, I., Marunduh, S. \& Wungouw, H.

2014. Perbandingan Denyut Nadi

Antara Penduduk Yang Tinggal Di

Dataran Tinggi Dan Dataran

Rendah. Jurnal E-Biomedik, 2.

Khayyat, S. M., Khayyat, S. M. S.,

Alhazmi, R. S. H., Mohamed, M. M.

\& Hadi, M. A. J. P. O. 2017.

Predictors Of Medication Adherence

And Blood Pressure Control Among

Saudi Hypertensive Patients

Attending Primary Care Clinics: A

Cross-Sectional Study. 12.

Marshall, I. J., Wolfe, C. D. A. \& Mckevitt,

C. 2012. Lay Perspectives On

Hypertension And Drug Adherence:

Systematic Review Of Qualitative

Research. 345, E3953.

Meshram, I., Arlappa, N., Balkrishna, N.,

Rao, K., Laxmaiah, A. \& Brahmam,

G. J. J. O. P. M. 2012. Prevalence Of

Hypertension, Its Correlates And

Awareness Among Adult Tribal

Population Of Kerala State, India.

58, 255.

Organization, W. H. 2013. Global Brief On

Hypertension.

Pekalongan, D. K. 2017. Data Penyakit

Tidak Menular. In: Ptm (Ed.).
Pekalongan: Dinkes Kabupaten Pekalongan.

Pekalongan, P. K. 2011a. Peta Dan Profil

Kecamatan Bojong [Online].

Pekalongan: Dipkominfo Kabupaten

Peklongan. Available:

http://pekalongankab.go.id/v2/pemer

intahan/deskripsi-wilayah/peta-

wilayah/510-peta-dan-profil-

kecamatan-bojong [Accessed 15

April 2019].

Pekalongan, P. K. 2011b. Peta Dan Profil

Kecamatan Doro [Online].

Pekalongan: Dipkominfo Kabupaten

Peklongan. Available:

Http://Pekalongankab.Go.Id/V2/Pe

merintahan/Deskripsi-Wilayah/Peta-

Wilayah/512-Peta-Dan-Profil-

Kecamatan-Doro [Accessed 15 April 2019].

Puspita, E. 2016. Faktor-Faktor Yang

Berhubungan Dengan Kepatuhan

Penderita Hipertensi Dalam

Menjalani Pengobatan (Studi Kasus

Di Puskesmas Gunungpati Kota

Semarang). Universitas Negeri

Semarang.

Ri, K. K. 2018. Hasil Utama Riskesdas 2018. In: Kesehatan, B. P. D. P.

(Ed.). Jakarta: Kementrian

Kesehatan Republik Indonesia.

Saputra, O. \& Anam, K. J. J. M. 2016.

Gaya Hidup Sebagai Faktor Risiko

Hipertensi Pada Masyarakat Pesisir

Pantai. 5, 118-123.

Son, P., Quang, N., Viet, N., Khai, P., Wall,

S., Weinehall, L., Bonita, R. \&

Byass, P. J. J. O. H. H. 2012.

Prevalence, Awareness, Treatment

And Control Of Hypertension In

Vietnam-Results From A National

Survey. 26, 268-280.

Susan, S. 2011. Keperawatan Medikal

Bedah Brunner \& Suddarth. Alih

Bahasa: Devi Yulianti \& Amelia

Kimin.

Triguna, I. P. B. \& Sudhana, I. W. J. E.-J.

M. U. 2013. Gambaran Kepatuhan

Minum Obat Antihipertensi Pada 
Jurnal Ilmiah Kesehatan Vol XIII, No I, Maret 2020 ISSN 1978-3167, E-ISSN 2580-135X

Pasien Hipertensi Di Wilayah Kerja

Puskesmas Petang Ii, Kabupaten

Badung Periode Juli-Agustus 2013.

Wang, J., Zhang, L., Wang, F., Liu, L. \&

Wang, H. J. A. J. O. H. 2014.

Prevalence, Awareness, Treatment,

And Control Of Hypertension In

China: Results From A National

Survey. 27, 1355-1361. 